\title{
Effect of Heterogeneity on the Measurements of Mechanical Properties of Composite Coatings
}

\author{
LU Xiaojuan ${ }^{1}$ \\ ${ }^{1}$ School of Environment Science and Engineering, North China Electric Power University, Mailbox \\ 253, No.689 Huadian Road, Baoding, Hebei, P. R. China \\ Email: xiaojuanlv@hotmail.com
}

Keywords: Nanoindentation; Porous; Composite coating; Indentation size effect

\begin{abstract}
The heterogeneity of porous features and different phases, especially porous features are important in the performance of ceramic coatings as thermal protection. In evaluation of mechanical properties of porous composite coatings by using nanoindentation, the effect of heterogeneity needs to be clarified. In this study, $\mathrm{YSZ} / \mathrm{Al}_{2} \mathrm{O}_{3}$ composite coatings prepared by EPD and sintered subsequently at high temperatures are investigated. Load-displacement curves are pores and particle fractures sensitive, but independent of different phases. The measured mechanical properties are strongly dependent on the penetration depth chosen. In order to cover all the microstructural features in the $\mathrm{YSZ} / \mathrm{Al}_{2} \mathrm{O}_{3}$ composite coatings, a penetration depth larger than $1000 \mathrm{~nm}$ was required to determine the global mechanical properties.
\end{abstract}

\section{Introduction}

Ceramic materials, resistant to high temperature and corrosive environment, are often coated on metal components in harsh working conditions as protection. The mechanical properties of coatings, such as modulus and hardness are essential in evaluating the coating performance. Various techniques have been developed for evaluating the mechanical properties of coatings, among which, a high-resolution, depth-sensing indentation technique has been successful in the examination of ceramic coatings [1-3]. It allows a determination of mechanical properties locally on small structural features in the materials due to its small measurement length scale (micrometer or nanometre) and quasi-nondestructive nature. The method relies on there being an accurate determination of the initial contact of the indenter with the specimen surface, corrections for compliance of the loading column, corrections for bluntness of the indenter, and corrections for materials-related issues such as sink-in, pile-up, residual stress and indentation size effect (the hardness decreases with the increase of depth) etc [4]. The first two issues and the sink-in have been corrected in Pharr-Oliver method. The bluntness of the indenter can be calibrated by performing an indentation on a reference material-silicon. The influence of the pile-up has been studied using finite element simulation [5-8] combined with imaging the contact impression which found that the contact area can be underestimated as much as $60 \%$ when the pile-up is significant [5]. The effect of pile-up cannot be ignored when using the indentation technique to measure hardness and modulus. The measured mechanical properties, especially for thin films, are strongly dependent of the penetration depth $[1,2,9]$. Thereby it is important to correct the pile-up, residual stress and find an applicable penetration depth in order to obtain accurate mechanical properties.

In this work, YSZ/ $\mathrm{Al}_{2} \mathrm{O}_{3}$ composite coatings were fabricated by using electrophoretic deposition and sintered subsequently at high temperatures. The effects of pile-up and residual stress were studied and found to be insignificant in this type of coatings [10]. Load-displacement curves are sensitive to the pores and the collapse of pores would affect the measurement of mechanical properties. The effect of penetration depth has been investigated and the mechanical properties obtained are strongly dependent on the penetration depth. To measure the macroscopic mechanical properties of a material, an indentation-size effect can be avoided by using a large enough penetration depth, $>1000 \mathrm{~nm}$ in this case. 


\section{Experimentals}

Yttria-stabilized zirconia/alumina $\left(\mathrm{YSZ} / \mathrm{Al}_{2} \mathrm{O}_{3}\right)$ composite coatings were prepared from a mixture of $95 \mathrm{wt} \%$ YSZ powder $(\sim 0.3 \mu \mathrm{m}$, HSY-8, Daiichi Kigenso Kagaku Kogyo, Japan) and $5 \mathrm{wt} \% \mathrm{Al}$ powder $(<6 \mu \mathrm{m}$, Alpoco, UK) by electrophoretic deposition (EPD), which is detailed in elsewhere [11], followed by thermal treatment at high temperatures. The green coatings were dried at room temperature for $24 \mathrm{~h}$ before they were sintered in air at $1250^{\circ} \mathrm{C}, 1400^{\circ} \mathrm{C}$ and $1450^{\circ} \mathrm{C}$ for $4 \mathrm{~h}$. In parallel, two bulk samples with same compositions as coatings prepared above were dry-pressed and sintered at $1450 \mathrm{oC}$ and $1500 \mathrm{oC}$ for 2 hours for comparison. The coatings prepared are all aimed to be $\sim 200 \mu \mathrm{m}$ and the bulk samples are $2000 \mu \mathrm{m}$ in thickness and $10000 \mu \mathrm{m}$ in diameter.

JSM 6500F thermal field emission scanning electron microscope, fitted with an Oxford Inca 300 EDS system was used to examine the microstructures of composite coatings. Nanoindentation experiments were carried out by employing a Nano Indenter ${ }^{\circledR}$ XP (Nano Instruments, MTS systems corporation, USA). For indentation we used a Berkovich indenter with a total included angle of $142.3^{\circ}$ and a half angle of $65.35^{\circ}$ calibrated with a standard silica specimen by running a standard continuous stiffness measurement (CSM). The load was held at $70 \%$ of maximum load for $60 \mathrm{~s}$ to correct for thermal drift. Tip geometry and machine compliance were calibrated prior to the test. Hardness and Young’s modulus were determined using the Oliver and Pharr analysis method [5].

\section{Results and Discussion}

The microstructures of the $\mathrm{YSZ} / \mathrm{Al}_{2} \mathrm{O}_{3}$ composite coatings sintered at $1250^{\circ} \mathrm{C}$ (with the impression of a $2 \mu \mathrm{m}$ penetration depth indentation), $1400^{\circ} \mathrm{C}$ and $1450^{\circ} \mathrm{C}$ for $4 \mathrm{~h}$ are shown in Fig.1. It can be seen from Fig. 1 (a) that the coating sintered at $1250^{\circ} \mathrm{C}$ is porous and many small crack-like pores are present on the top surface. In comparison with the one sintered at $1250 \mathrm{oC}$, large pores are formed while small pores are closed on those sintered at higher temperatures. For the coatings sintered at $1250^{\circ} \mathrm{C}, 1400^{\circ} \mathrm{C}$ and $1450^{\circ} \mathrm{C}$, the porosity was measured to be $41 \%, 28 \%$ and $18 \%$ by the weight-volume method, respectively. And the average grain size measured by SEM is $0.4 \mu \mathrm{m}$, $0.6 \mu \mathrm{m}$ and $0.8 \mu \mathrm{m}$ respectively. And also from Fig. 1(a), it can be seen that the diameter of a $2 \mu \mathrm{m}$ penetration depth impression on the coating is about $8 \mu \mathrm{m}$. Thus resulting contact area between the Berkovich indenter and the sample is large enough to cover all the microstructural features of the coatings.

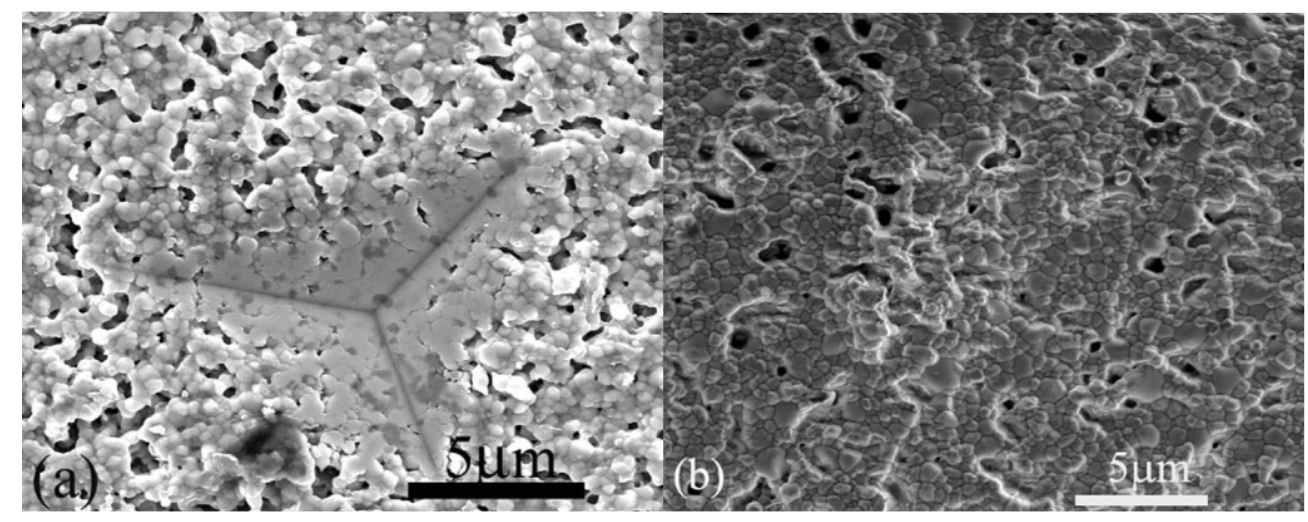




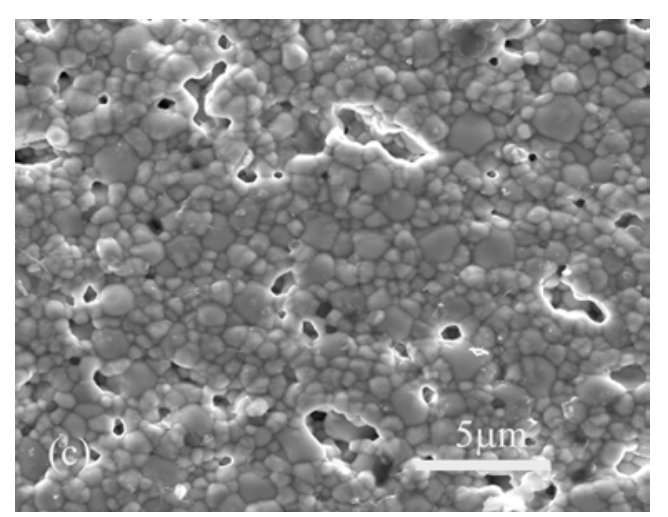

Fig.1 SEM secondary electron micrographs of $\mathrm{YSZ} / \mathrm{Al}_{2} \mathrm{O}_{3}$ composite coating sintered at (a) $1250^{\circ} \mathrm{C}$, (b) $1400^{\circ} \mathrm{C}$ and (c) $1450^{\circ} \mathrm{C}$.

The load-displacement curves of the composite coatings sintered at various temperatures are shown in Fig.2. It was found that the one sintered at lower temperature tend to generate a load-displacement curve with more kinks ( the inset is the enlarged one sintered at $1250^{\circ} \mathrm{C}$ ), while the ones sintered at higher temperature have less kinks presented. These kinks may be due to the presence of pores which might cause micro-collapse underneath the indenter and possible particles fracture occured, or the presence of two different phases which would lead to a sudden change in the stress-strain response in the $\mathrm{YSZ} / \mathrm{Al}_{2} \mathrm{O}_{3}$ composite coating.

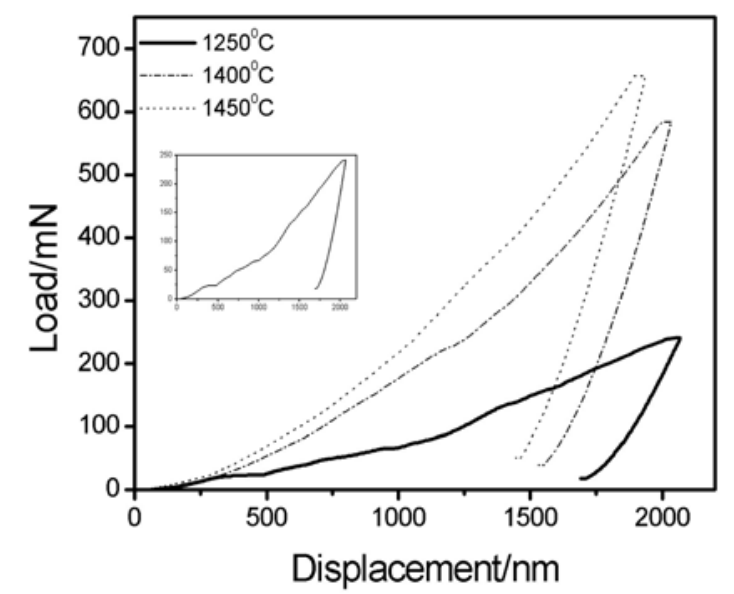

Fig.2 Load-displacement curves of $\mathrm{YSZ} / \mathrm{Al}_{2} \mathrm{O}_{3}$ composite coatings

In order to clarify whether the presence of different phases would account for the kinks or not, two bulk samples with same compositions have been prepared. These two bulk samples which would still have different phases are dry pressed and sintered at $1450^{\circ} \mathrm{C}$ and $1500^{\circ} \mathrm{C}$ respectively, resulting in a theoretical density higher than $95 \%$ to exclude the effect of pores. SEM images of the top surfaces are shown in Fig.3. It can be seen that both samples are very dense, but the sample sintered at $1450^{\circ} \mathrm{C}$ has more uniform and smaller grains than the one sintered at $1500^{\circ} \mathrm{C}$. The grain size of samples sintered at $1450^{\circ} \mathrm{C}$ is in the range of $0.4-0.9 \mu \mathrm{m}$, while the grains of samples sintered at $1500^{\circ} \mathrm{C}$ seem to fall into two ranges: smaller ones are around $1 \mu \mathrm{m}$ and large ones are about $4 \mu \mathrm{m}$.

Such samples were examined by indentation and the load-displacement curves (Fig.4) were found to be fairly smooth and kink-free. The only difference observed between the two curves is that under the same load of $650 \mathrm{mN}$, the sample sintered at $1500^{\circ} \mathrm{C}$ was penetrated into a shallower depth of $1.6 \mu \mathrm{m}$ than the one sintered at $1450^{\circ} \mathrm{C}$, which was penetrated into $1.85 \mu \mathrm{m}$. The dimension of grains has little effects on the appearance of the curves. This implies that the kinks observed in Fig.2 are independent of different phases and grain size, must be mainly due to the presence of the pores and particles fractures in the microstructure. 


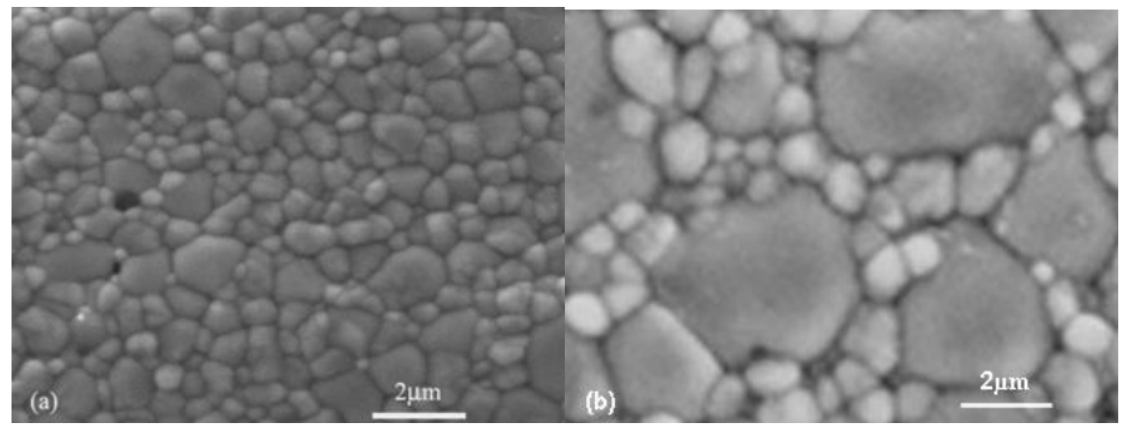

Fig.3 Top surfaces of bulk YSZ/ $/ \mathrm{Al}_{2} \mathrm{O}_{3}$ samples sintered at (a) $1450^{\circ} \mathrm{C}$ and (b) $1500^{\circ} \mathrm{C}$

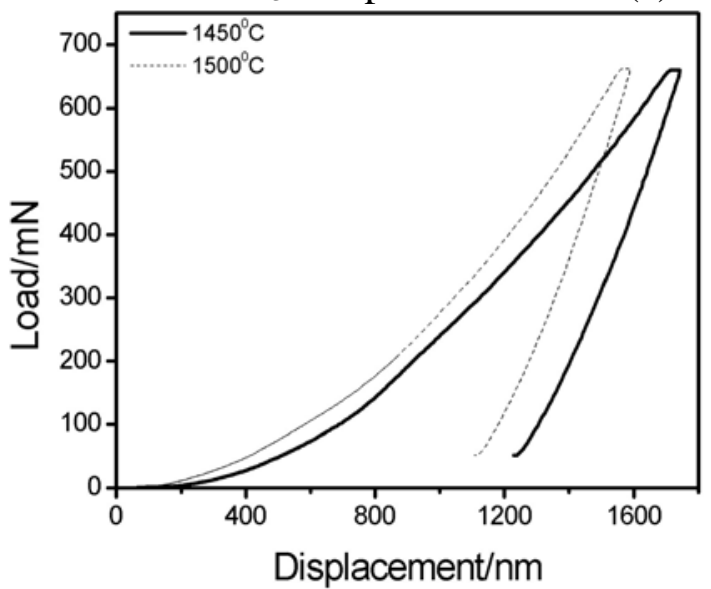

Fig.4 Load-displacement curves of dense $\mathrm{YSZ} / \mathrm{Al}_{2} \mathrm{O}_{3}$ bulk samples

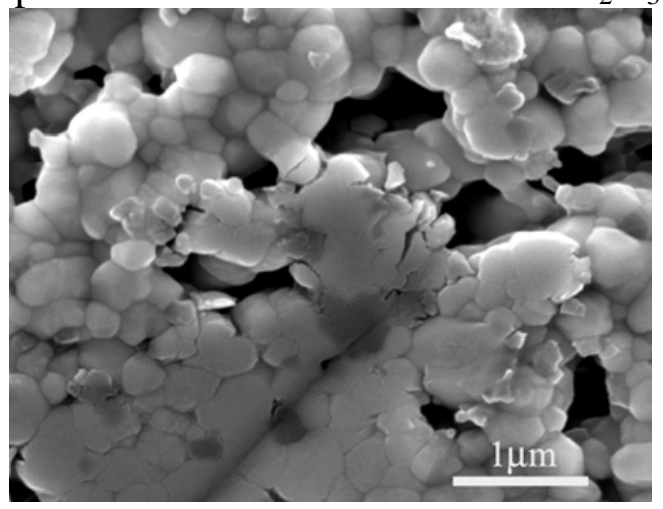

Fig.5 An impression of the indentation on a composite coating sintered at $1250^{\circ} \mathrm{C}$

Therefore, the impressions of the indentation on $\mathrm{YSZ} / \mathrm{Al}_{2} \mathrm{O}_{3}$ composite coatings sintered at $1250^{\circ} \mathrm{C}$ were examined closely, shown in Fig.5. The area underneath the indenter appeared to be much denser than the rest areas. This evident densified feature is the evidence of the collapse of pores during the indentation. When the pores collapsed, the load applied remained constant but the displacement would continue to increase as a result of collapsed pores. Thus, the collapse of pores would lead to a sudden change in the load-displacement curves, appeared as kinks. Also some small particles fractures have been observed nearby the impression of the indentation. Therefore, it can be concluded that the kinks in porous composite coatings are mainly attributed to the collapse of pores and small particles fracture occurred upon indentation, have little to do with the different phases.

\section{Conclusion}

Porous features are essential to the ceramic coatings on metal components as thermal protection, while they also render a challenge for the characterization of mechanical properties by nanoindentation. Load-displacement curves obtained in nanoindentation are found to be independent of different phases, while sensitive to the presence of sub-micrometer pores and small particle fractures. The pores tend to collapse underneath the indenter and result in a large scatter in the acquired data, thus an applicable penetration depth is necessary for the accurate measurements 
in porous coatings. In order to cover all the microstructural features in the porous $\mathrm{YSZ} / \mathrm{Al}_{2} \mathrm{O}_{3}$ composite coatings, a penetration depth larger than $1000 \mathrm{~nm}$ was required to determine the global mechanical properties.

\section{Acknowledgement}

This research was financially supported by the Natural Science Foundation of Hebei Province, China (No.E2013502272) and the fundamental research funds for the central universities (No. 2015ZD25).

\section{References}

[1] 1. R. Ghasemi, R. Shoja-Razavi, R. Mozafarinia, H. Jamali: Ceram. Int. Vol. 39 (2013), p. 8805.

[2] P. Carpio, E. Rayón, L. Pawłowski, A. Cattini, R. Benavente, E. Bannier, M. D. Salvador, and E. Sánchez: Surf. Coat. Technol. Vol. 220 (2013), p. 237.

[3] E. Lugscheider, K. Bobzin, A. Barwulf, A. Etzkorn: Surf. Coat. Technol. Vol. 138 (2001), p. 9.

[4] A. C. Fischer-Cripps: Surf. Coat. Technol. Vol. 200 (2006), p. 4153.

[5] A. Bolshakov, G. M. Pharr: J. Mater. Res. Vol. 13 (1998), p. 1049.

[6] S. H. Kim, , B. W. Lee, Y. Choi, D. Kwon: Mater. Sci. Eng. A, Vol. 415 (2006), p. 59.

[7] B. Taljat, and G. M. Pharr: Int. J. Solids Structures, Vol. 41 (2004), p. 891.

[8] W. C. Oliver, and G. M. Pharr: J. Mater. Sci. Vol. 19 (2004), p. 3.

[9] J. Nohava, R. Mušálek, J. Matějiček, M. Vilémová: Surf. Coat. Technol. Vol. 240 (2014), p. 243.

[10] X.-J. Lu, X. Wang, P. Xiao: Thin Solid Films, Vol. 494 (2006), p. 223.

[11] X. Lu: Int. J. Min. Met. Mater. Vol. 21 (2014), p. 1127.

[12] W. C. Oliver, G. M. Pharr: J. Mater. Res. Vol. 7 (1992), p.1564.

[13] N. Ramakrishnan, V. S. Arunachalam: J. Mater. Sci. Vol. 25 (1990), p. 3930.

[14] A. Atkinson, A. Selcuk: Solid State Ionics, Vol. 134 (2000), p. 59.

[15] Green, D. J., An Introduction to the Mechanical Properties of Ceramics, Cambridge University Press, Cambridge, 1998, p.25.

[16] T. Nakamura, G. Qian, C. C. Berndt: J. Am. Ceram. Soc. Vol. 83 (2000), p.57 